\title{
Neuromodulation for Obsessive-Compulsive Disorder
}

\author{
Kyle A. B. Lapidus • Emily R. Stern • Heather A. Berlin • \\ Wayne K. Goodman
}

Published online: 1 July 2014

(C) The American Society for Experimental NeuroTherapeutics, Inc. 2014

\begin{abstract}
Neuromodulation shows increasing promise in the treatment of psychiatric disorders, particularly obsessivecompulsive disorder (OCD). Development of tools and techniques including deep brain stimulation, transcranial magnetic stimulation, and electroconvulsive therapy may yield additional options for patients who fail to respond to standard treatments. This article reviews the motivation for and use of these treatments in OCD. We begin with a brief description of the illness followed by discussion of the circuit models thought to underlie the disorder. These circuits provide targets for intervention. Basal ganglia and talamocortical pathophysiology, including cortico-striato-thalamo-cortical loops is a focus of this discussion. Neuroimaging findings and historical treatments that led to the use of neuromodulation for OCD are presented. We then present evidence from neuromodulation studies using deep brain stimulation, electroconvulsive therapy, and transcranial magnetic stimulation, with targets including nucleus accumbens, subthalamic nucleus inferior thalamic peduncle, dorsolateral prefrontal cortex, supplementary motor area, and orbitofrontal cortex. Finally, we explore potential future neuromodulation approaches that may further refine and improve treatment.
\end{abstract}

Keywords Obsessive-compulsive disorder (OCD) . Deep brain stimulation (DBS) · Electroconvulsive therapy (ECT) · Transcranial magnetic stimulation (TMS) · Neuromodulation

K. A. B. Lapidus $(\triangle) \cdot$ E. R. Stern $\cdot$ H. A. Berlin $\cdot$ W. K. Goodman Departments of Psychiatry and Neuroscience, Icahn School of Medicine at Mount Sinai, One Gustave L. Levy Place, New York, NY 10029, USA

e-mail: kylelapidus@gmail.com

\section{Introduction: Obsessive-Compulsive Disorder}

Obsessive-compulsive disorder (OCD) is a potentially disabling disorder and a leading cause of morbidity worldwide that occurs in approximately $1-3 \%$ of the population $[1,2]$. This disorder is characterized by obsessions and compulsions [3]. Obsessions, which include persistent, distressing thoughts, images, or impulses that affected people generally recognize as products of their own minds, cause substantial anxiety and distress. Patients with OCD attempt to neutralize the anxiety and discomfort from the obsessions with compulsions, repetitive behaviors intended to reduce or prevent distress and undesirable situations or events. Recent changes in diagnostic criteria have involved reclassification of OCD from being an "anxiety" disorder to a new group of "obsessive-compulsive and related disorders" with a focus on repetitive behaviors [4]. This change is potentially important when considering the underlying neurocircuitry and potential treatments in OCD.

Unfortunately, inadequate animal models for OCD limit the development of therapeutics. In humans, inadequate pharmacological treatments have motivated circuit-based treatments in refractory patients. These approaches originally focused on ablative surgery, in which a variety of techniques have been used to destroy brain tissue, producing an irreversible lesion. More recently, interest has grown in therapeutic neuromodulation, where electricity is administered to elicit changes in neuronal function. Building on the history of lesion-based neurosurgical treatments in OCD, surgical neuromodulation or electricity delivered by implanted devices, has been used as a favorable alternative to ablative surgery. Less invasive techniques that do not require surgery, including currents applied to the scalp and magnetic fields, have also been investigated as potential treatments for OCD. 


\section{Neurocircuitry of OCD}

\section{Circuit Models}

Following decades of research, the neurocircuitry of OCD remains a topic of active investigation. Cortico-striatothalamo-cortical (CSTC) loops have been implicated in the pathophysiology of a variety of psychiatric symptoms (Fig. 1). The development of Parkinsonism in abusers of 1-methyl-4phenyl-1,2,3,6-tetrahydropyridine provided early evidence for the importance of these loops $[5,6]$. Based on evidence from labeling, lesion, and single-cell recording studies, in the mid1980s Alexander et al. [7] proposed at least 5 parallel but functionally segregated basal ganglia-thalamocortical circuits. While additional data has led to revision of the model of Alexander et al. [7], including less segregated loops and additional brain regions, it remains conceptually important [8]. In this model, the cortical areas involved determine the names of the circuits, and each circuit functions independently to facilitate unique physiological functions. These circuits remain distinct through the basal ganglia and have individual cortical projections via both "direct" and "indirect" pathways [9]. The "direct" pathway includes two excitatory and two inhibitory connections, forming a positive feedback loop in which cortical activity disinhibits the thalamus to activate the cortex. Because the "indirect" pathway has one excitatory and three inhibitory connections, cortical activity results in inhibition of both thalamus and cortex; therefore, the pathway functions as a negative feedback loop. The "motor" circuit hinges primarily on the putamen, which receives projections from the motor and somatosensory cortices. The putamen projects reciprocally to the cortex and also to the globus pallidus and substantia nigra, which, in turn, project to the thalamus. Other loops include "oculomotor", "dorsolateral prefrontal", "lateral orbitofrontal", and "anterior cingulate" cortices.

The model of Alexander et al. [7] contributed to the development of surgical neuromodulatory interventions for Parkinson's disease, and has supported the use of surgical interventions in OCD. In OCD, CSTC functions have been strongly implicated to mediate symptoms and treatment response. Evidence suggesting that pharmacological treatments reduce caudate hypermetabolism when they improve symptoms indicates the importance of the dysregulation of this circuit in OCD [11]. Several additional lines of evidence support CSTC involvement in this disorder. Common features

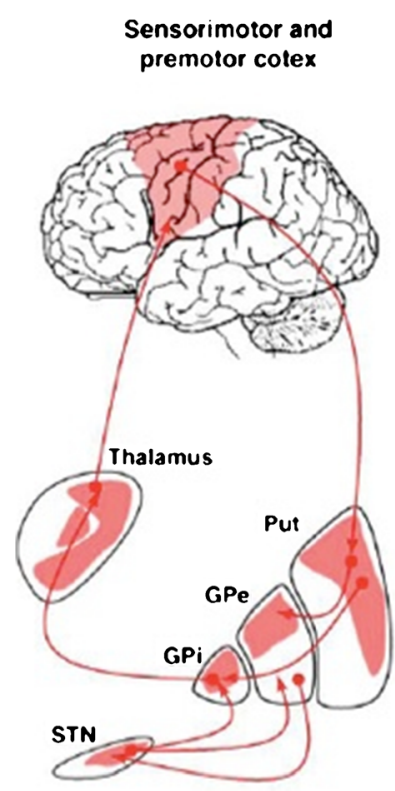

(a) Motor circuit

\section{Dorsolateral prefrontal and lateral orbitofrontal cortex}

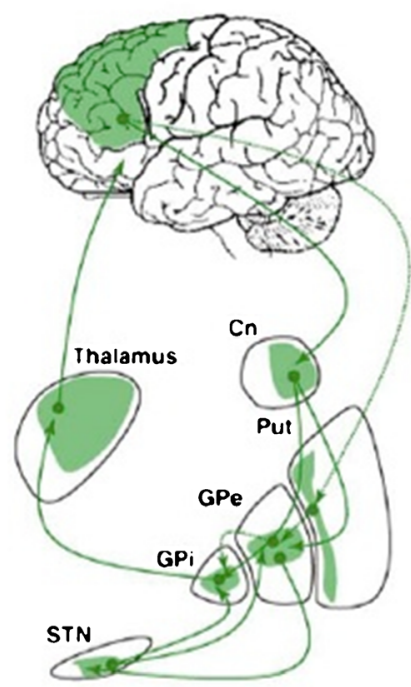

(b) Associative circuit

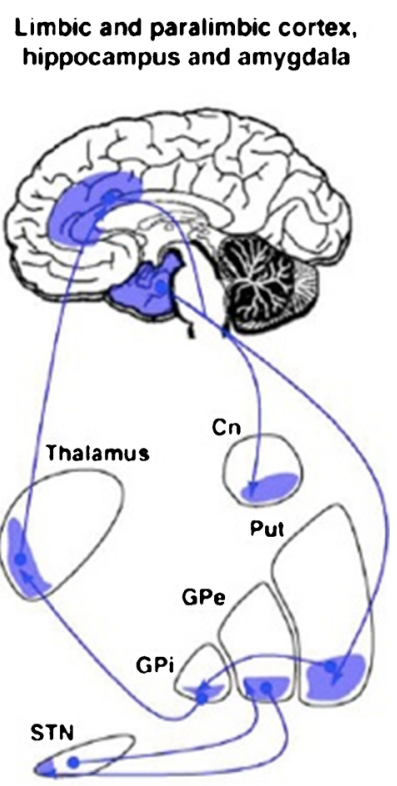

(c) Limbic circuit
Fig. 1 Neurocircuitry: cortico-striato-thalamocortical loops. Pathways in motor, associative, and limbic circuitry. (a) Motor circuit. Neurons from the sensorimotor cortex project to the posterolateral putamen (Put), which, in turn, projects to the posterolateral region of the target nuclei: (i) the direct circuit to the globus pallidus pars interna (GPi) and (ii) the indirect circuit connecting the posterior putamen (Put) to the globus pallidus pars externa (GPe), the subthalamic nucleus (STN) and the GPi. The GPi is the primary output nucleus of the basal ganglia to the cortex via the ventrolateral thalamus. (b) Associative circuit. This circuit originates in the dorsolateral prefrontal and lateral orbitofrontal cortices; projections include the striatal caudate nucleus $(\mathrm{Cn})$ and anteromedial portion of the Put, and subsequently projections to the dorsomedial region of the GPi, and anteromedial portions of the GPe and STN. These, in turn, project onto the GPi and back to the cortex via the ventral anterior nuclei of the thalamus. (c) Limbic circuit. Here, the hippocampus, amygdala, paralimbic and limbic cortices project to the ventral striatum (ventral portion of the caudate and putamen, including nucleus accumbens). The ventral striatum projects to the limbic portion of the GPe, medioventral STN, ventral GPi, and to the cortex via the mediodorsal nucleus of the thalamus. Reproduced with permission from Krack et al. [10] 
and neural substrates are shared between OCD and movement disorders; neuronal areas involved in motor function have been implicated in OCD pathogenesis since early observations of the illness. Tourette's disorder, associated with both motor tics and OCD-like symptoms, supports the idea that a single neural substrate can produce both motor and psychiatric illness. Tourette's and OCD exhibit significant comorbidity and genetic associations, highlighting the etiological importance of the basal ganglia in OCD symptoms [12-14]. Basal ganglia circuit dysfunction is thought to play a role in the generation of both motor and OCD symptoms in Tourette's syndrome $[15,16]$.

The efficacy of serotonergic pharmacotherapies [e.g., selective serotonin reuptake inhibitors (SSRIs)] also supports a role for CSTC loops in the pathogenesis of OCD [17]. High levels of 5-hydroxytryptamine receptor $2 \mathrm{~A}$ and 5hydroxytryptamine receptor $2 \mathrm{C}$ expression in the striatum offer a mechanism by which serotonergic agents could influence CSTC circuit function [18]. Other neurotransmitters in CSTC circuits are also likely to influence OCD susceptibility, chronicity, severity, and treatment response. Dopaminergic dysfunction has been particularly implicated [19]. Higher basal ganglia dopamine transporter binding ratios have been reported in OCD [20], and decreased caudate D2 binding [21], suggesting alterations of synaptic dopamine in the basal ganglia.

Other CSTC neurotransmitter systems that may have pathophysiological importance include glutatmate, substance $\mathrm{P}$, acetylcholine, and endogenous opioids [22]. Of these, glutamate dysfunction has been most strongly suggested. Magnetic resonance spectroscopy has identified abnormalities of caudate glutamate in patients with OCD, and SSRI treatment corrects these abnormalities [23]. These measurements include both intracellular and synaptic glutamate, and are consistent with increased caudate activity previously reported in OCD. Gene linkage analyses of patients with OCD and their families also support a pathophysiological role for glutamate [24-27]. Also, preliminary evidence suggests that glutamatergic agents such as riluzole and ketamine may be useful in OCD [28-31].

It is clear that no single anatomic or physiological defect will likely be identified to be responsible for the pathogenesis of complex psychiatric symptoms (e.g., decreased dopamine in PD). More likely, OCD symptoms may involve multiple neural circuits. A systems-based approach is critical in assessing the clinical data to identify targets for neuromodulation. The multicircuit model hypothesizes that the primary pathogenic mechanism is dysregulation of the basal ganglia/limbic striatal circuits that modulate neuronal activity in and between the orbitofrontal and anterior cingulate cortex (ACC), as well as the medial, dorsomedial (DM), and anterior thalamic nuclei [32]. This neuronal model of OCD includes 3 components. The first involves a reciprocal positive feedback loop between the orbital (OFC) and prefrontal cortex (PFC) and the DM thalamic nucleus, via the anterior limb of the internal capsule. The corticothalamic projection is excitatory and mediated primarily by glutamate and aspartate. The reciprocal thalamocortical pathway's neurotransmitter is also thought to be excitatory, and likely glutamatergic [32, 33].

The second component of this model involves the OFC/ PFC, the ventral caudate, the DM pallidum, and the intralaminar, anterior, and DM thalamic nuclei [7]. Projections from the ventral striatum to the DM pallidum use multiple transmitters. However, the output of this pathway from the DM pallidum to the thalamus is primarily inhibitory and gamma-aminobutyric acid (GABA)-mediated [34, 35]. The GABAergic inhibition is thought to modulate the excitatory positive feedback loop described above. The importance of dopamine and glutamate in this pathway has also been demonstrated [36], and inhibitory serotonergic projections from midbrain dorsal raphe nuclei to the striatum are also involved in this model [37, 38].

The third component involves the limbic system and the Papez circuit. In 1937, Papez [39] proposed that cerebral cortical activity is essential for emotional experience and that emotional expression relies on the integrative action of the hypothalamus. Papez created a model to connect these structures based on his neuroanatomic observations. This connects the hippocampal formation to the mammillary body, which projects via the mammilothalamic tract to the anterior thalamic nuclei; this then connects to the cingulate gyrus. In the OCD model discussed previously, the DM nuclei and orbitofrontal cortex connect extensively to the Papez circuit. Also, ACC projections to the nucleus accumbens (NAc) may mediate some of the emotional and anxiety components of OCD.

\section{Functional Neuroimaging in OCD}

Over the last several decades, neuroimaging techniques, such as functional magnetic resonance imaging (fMRI) and positron emission tomography (PET), have been used to investigate neurocircuit functioning in OCD; these studies provide further support for pathophysiological circuit models. A role for CSTC loops in OCD has been suggested in both neutral (i.e., the baseline obsessional thoughts and compulsive behaviors of patients with OCD) and provoked (i.e., following presentation of a stimulus that exacerbates the patient's symptoms) states. PET and fMRI studies have shown that effective treatments, including medications such as SSRIs and behavioral therapy, correct the abnormally increased metabolism seen in these areas [40, 41]. Endogenous activation patterns also respond following surgical neuromodulatory treatments, suggesting that efficacy is associated with metabolic normalization [42]. 


\section{Neuromodulatory Approaches}

\section{Deep Brain Stimulation}

Understanding of circuit and node dysfunction in OCD suggests targets and approaches for intervention. Neurosurgical stimulation initially targeted sites where lesioning or ablative surgery suggested efficacy, though, clearly, neuromodulation has significant advantages over ablative treatments. Stimulation can be adjusted and reversed, while blinding in clinical trials is facilitated by the ability to switch stimulation on or off without the patient's awareness. Still, DBS treatment has risks, including the induction of hypomania, so frequent follow-up is required. Importantly, DBS involves neurosurgical intervention with craniotomy, and associated risks include infection, hemorrhage, and edema, which can lead to transient or permanent neurological sequelae, or even death.

Early attempts to treat OCD symptoms using deep-brain stimulation (DBS) often suffered from the lack of stringent selection criteria, rigorous assessments, and optimal imaging. Such studies may have limited value for assessing efficacy, but can help guide future investigations. In 1979, lowfrequency $(5 \mathrm{~Hz})$ bilateral mediothalamic DBS was used for control of phobias [43]. This ameliorated phobias and obsessional symptoms at 1-year follow-up. Also in the 1970s, cerebellar vermis stimulation was the first procedure to use a network approach rather than addressing a particular "target"; it was designed to upregulate septal activity while downregulating amygdala activity. At least a moderate response was reported in 5/5 obsessional patients after 2.5 years [43]. Stimulation of white matter around the cingulum was associated with emotional responses following early trials in 135 patients with a variety of psychiatric diagnoses [44].

Psychiatric and cognitive effects of DBS in movement disorder surgery also indicated that modulation of the neural systems underlying psychiatric illness can be accomplished with electrical stimulation. DBS to the subthalamic nucleus (STN), widely used in Parkinson's disease, can affect limbic, dorsolateral prefrontal, and orbitofrontal loops that all pass through the STN. In addition to affecting motor function, STN stimulation would be expected to alter neuropsychological function [7]. Accordingly, mood and anxiety improvements have been widely noted in patients receiving STN DBS for Parkinson's disease $[45,46]$. The ventromedial and medial portions of the STN, considered associative and limbic areas, may have been involved, though surrounding or communicating structures such as the lateral hypothalamus or ventral tegmental area may also contribute. Stimulation of either of these structures may activate dopaminergic and serotonergic structures related to the medial forebrain bundle, where direct stimulation has been reported to induce feelings of pleasure [47]. STN DBS also reduced obsessive and compulsive symptoms in patients with Parkinson's disease with a Yale-Brown
Obsessive Compulsive Scale (Y-BOCS) decrease from 32 to 1 in one case, and $58 \%$ or $64 \%$ decreases in 2 others [48, 49].

However, STN DBS has also been associated with exacerbations of psychiatric symptoms, including stimulationdependent depressive symptoms [50,51]. Mania, hypomania, anxiety symptoms, and psychosis have also been reported with STN DBS in Parkinson's patients [52-55]. DBS of the globus pallidus interna has elicited anxiolytic effects [56], and has also been associated with the relief of depressive symptoms in a patient with dyskinesia [57]. Similarly, in patients treated for comorbid Tourette's disorder, globus pallidus interna DBS resulted in improvement of OCD symptoms.

Although DBS is widely used in movement disorders, fewer studies have been performed primarily in treatment of psychiatric disorders $[58,59]$. In OCD, based on a review of 90 published cases, response rates appear to exceed 50\% [60]. A meta-analysis including DBS at all sites and targets $(n=64)$ found heterogeneity but demonstrated an overall significant benefit with an average improvement in score reduction of 2.77 SDs (95\% confidence interval 0.648-4.896) [61]. Currently, OCD is the only psychiatric disorder with US Food and Drug Administration status for DBS; this treatment has been granted a Humanitarian Device Exemption.

The first reports of DBS treatment primarily for psychiatric conditions, OCD and Tourette's syndrome, were published in 1999 [62, 63]. Stimulation of the anterior limb of the internal capsule in "targets [...] aimed for in capsulotomy" led to symptomatic improvement in 3/4 patients with OCD (Fig. 2). In another case series, $2 / 3$ patients responded with improvements in OCD symptoms following open-label treatment [64]. Another report included efficacy in a single patient with a 79\% reduction in scores on the Y-BOCS following 3 months of stimulation $[65,66]$. A case of ventral caudate stimulation also led to sustained improvements in OCD symptoms, anxiety, and depression $[67,68]$. In 6 severely symptomatic patients with OCD (baseline Y-BOCS $>30$ ) who received double-blinded, bilateral internal capsular stimulation [69], 3/6 patients met the response criteria - a 35\% reduction in Y-BOCS. Responders showed reductions in frontal metabolism, assessed by PET, after 3 months of stimulation, and experienced worsening of mood and OCD symptoms when stimulation was turned off. These data were republished in 2008, with additional data from 2 subsequently implanted patients and further follow-up [70]. No infections, deaths, hemorrhages, or significant changes in vegetative signs were reported. Mania was not observed, though disinhibition occurred, which responded to stimulation intensity decreases. Two additional cases also suggested a benefit for depressive symptoms, as well as Y-BOCS improvement [71]. Importantly, in 3 patients, no additional benefit was gained by providing cingulotomy combined with ventral capsule (VC)/ventral striatum (VS) stimulation [72].

Several international multicenter studies including 18 patients found that DBS to the VC/VS ameliorated OCD 


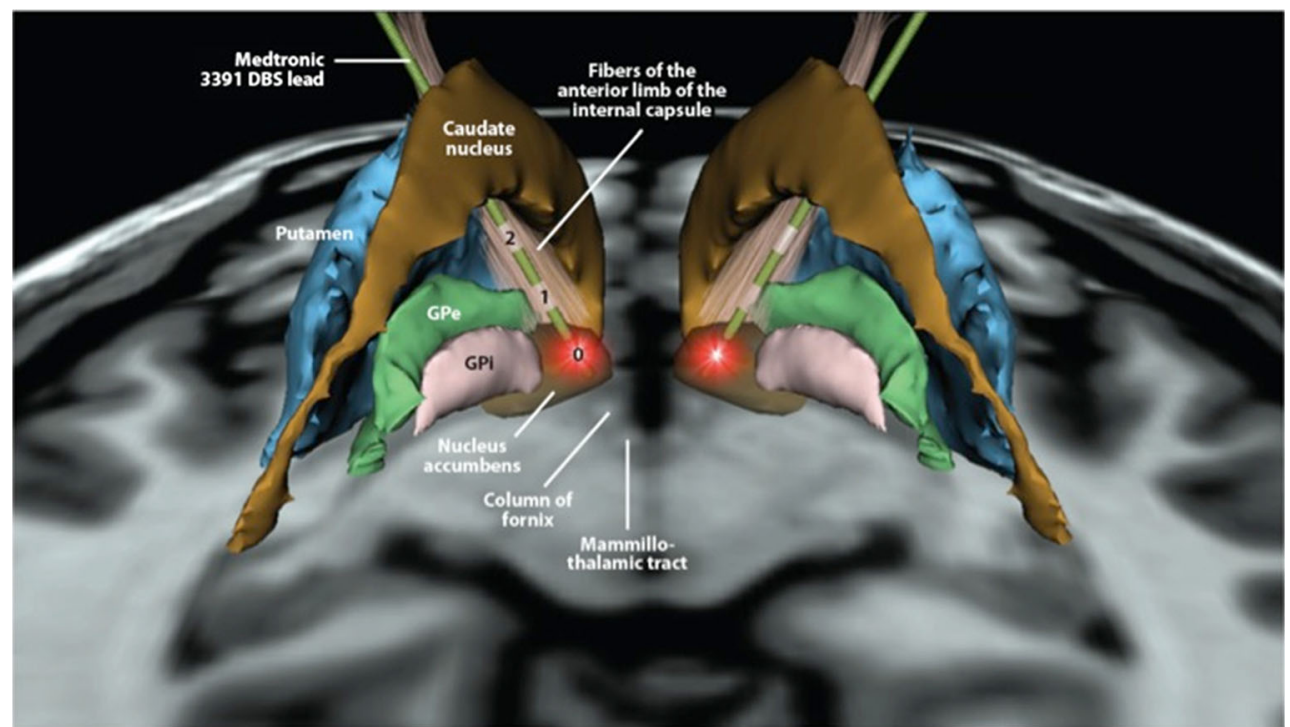

Fig. 2 Three-dimensional illustration of deep brain stimulation (DBS) in ventral capsule/ventral striatum. This model demonstrates leads and brain structures on the axial plane $5 \mathrm{~mm}$ below the intercommisural plane as viewed posterior to anterior. The trajectory of the leads follows the anterior limb of the internal capsule. Each lead has 4 contacts, but only

symptoms [73-75]. Later implantation dates were associated with greater efficacy, with response rates nearing $80 \%$ and a $60 \%$ decrease in Y-BOCS score. Depression and anxiety also improved significantly, though these studies included periods of open-label treatment in addition to controlled assessments [76]. Hypomania [77] and contralateral smiles have also been elicited through stimulation at this site, suggesting engagement with the reward circuitry [78]. These acute changes in mood have been found to predict response [79, 80]. Serious adverse events included 2 small hemorrhages without permanent sequelae, seizure managed with phenytoin, wound infection managed with antibiotics, and lead/extension breakage requiring replacement. Psychiatric adverse events occurred with both active and sham stimulation [81]. Functional changes detected using PET included stimulation-induced perfusion increases in ACC, OFC, striatum, pallidum, and thalamus. Similarly, electroencephalography (EEG) suggested dorsolateral PFC (DLPFC) responses to stimulation, and fMRI indicated blood flow changes in caudate, thalamus, and cingulate cortex that were associated with beneficial effects of stimulation in another case [82]. Importantly, stimulation discontinuation following pulse generator failure led to worsening of symptoms and adverse events, though in most cases symptoms still remained improved from baseline [83]. Fewer side effects were reported in open treatment protocols, which also demonstrated efficacy in 8 patients with improvements in symptom severity on the Y-BOCS (approximately 30\% and 60\%) and the Hamilton Depression Rating Scale [84, 85]. Furthermore, cognitive function has not been reported to decline and may improve following stimulation at this site [86].
3 are shown (contacts $\# 0, \# 1$, and $\# 2$ ); contact $\# 3$ is hidden by the caudate nucleus. The most ventral contact $(\# 0)$ is active, as represented by red radiating stimulation fields. $\mathrm{GPe}=$ globus pallidus externus; $\mathrm{GP} i=$ globus pallidus internus. Image courtesy of Kirk Finnis, Ph.D. [Medtronic Inc., USA]

The NAc has been targeted by other groups. Though initially considered to be nearby but structurally distinct, further analysis determined that in many patients receiving stimulation targeted to NAc the electrodes providing benefit were actually localized in the ventral anterior limb of the internal capsule (VC) [87]. Reports of open treatments with small numbers of patients (6 in total) suggested benefit in a high proportion of patients following NAc stimulation [88, 89]. In a double-blind, sham-controlled trial of unilateral DBS to the right NAc ( $\mathrm{n}=$ 10), illness severity, assessed by the Y-BOCS, following active stimulation differed significantly from baseline, but not from sham; only $10 \%$ of patients experienced a $>35 \%$ reduction in Y-BOCS score, while $40 \%$ experienced decreases between $25 \%$ and $35 \%$ over a 1 -year period [90]. However, after 3 years, $4 / 8$ patients experienced a $>35 \%$ reduction in Y-BOCS score, while 2 additional patients experienced a reduction of 25-35\% [91]. This group also reported fewer serious adverse events, with only transient symptoms of dysesthesia, agitation, anxiety, poor sleep, and suicidal thoughts in 1 patient [90]. Bilateral DBS of the NAc (i.e., $7 \mathrm{~mm}$ lateral to the midline, $3 \mathrm{~mm}$ anterior to the anterior commissure, and $4 \mathrm{~mm}$ inferior to the intercommissural line) produced better results in a study with open-label and sham-controlled phases [92], including response (Y-BOCS score decrease of $\geq 35 \%$ ) in $9 / 16$ patients and a $25 \%$ difference between active and sham treatments. Reported adverse events were relatively mild, and most frequently included hypomania ( 8 patients), numbness at incision site, or feeling of leads (7 each), and 1 transient wound infection. Impulsivity has also been noted as a side effect in several patients receiving NAc stimulation [93]. A follow-up report 
demonstrated associations between Y-BOCS score increases following DBS discontinuation and urinary-free cortisol excretion, a measure of hypothalamic-pituitary-adrenal axis activity [94]. Although measures of anxiety and depression also worsened following discontinuation, these did not correlate with changes in cortisol excretion. Recently, long-term open data from 16 patients were reported, and significant changes were noted in quality of life measures [95].

A multicenter 10-month, double-blind, crossover study of STN DBS was performed with 16 patients completing the assessment period [96]. One additional patient in this study developed infection requiring explantation prior to randomization and assessment. Relative to sham, active stimulation resulted in superior outcomes: decreases in symptom severity ( $>30 \%$ mean decrease on the Y-BOCS), and increases in overall function (Clinical Global Impression and Global Assessment of Functioning scores). Because of placement variations, some patients who benefitted in this study were actually stimulated in the internal capsule $(\mathrm{n}=4)$, zona incerta $(\mathrm{n}=$ 4), substantia nigra ( $\mathrm{n}=3)$, and $\mathrm{H}_{2}$ field of Forel $(\mathrm{n}=2)$. Fifteen serious adverse events were reported, including hemorrhage leading to permanent finger palsy in one patient and 2 infections, along with transient motor and psychiatric symptoms that resolved. Some psychiatric symptoms reported as adverse events also occurred during sham stimulation. A case series of 4 patients ( 2 from the prior study) reported 3 responders and 1 partial responder with $>60 \%$ mean improvement in Y-BOCS score, though side effects were still common [97]. Benefits associated with STN stimulation also correlated with the normalization of cortical hypermetabolism [42]. Also, abnormalities in single-unit neuronal activity were suggested and shown to reflect symptom severity while predicting response to STN DBS [98, 99].

Following DBS to the inferior thalamic peduncle, $5 / 5$ patients were reported to show meaningful response with mean a Y-BOCS score reduction of approximately 50\% [100]. An open follow-up including patients with psychiatric comorbidities (substance use disorders) found improvements in OCD symptoms in 6/6 patients at 12 months with mean a YBOCS score improvement of $>50 \%$ [101].

\section{Electroconvulsive Therapy}

Electroconvulsive therapy (ECT) has a significantly lower risk profile than DBS, though it requires general anesthesia and has side effects, including memory loss. For many decades, there has been inconsistency in reports and interpretation of data regarding the efficacy of ECT in OCD treatment. One early report included retrospective assessments of 31 patients with obsessional disorder who received ECT; 16 of these were improved at follow-up, though 10 stated that they thought ECT was not responsible for their improvement, including 1 who reported being worse following ECT, but subsequently improved [102]. Because only 3 of these patients "positively stated the [ECT] had helped them", the authors concluded that ECT was not appropriate for treating "obsessional states" without comorbid depression. Others reported that more than two thirds of patients with severe OCD but without major affective disorder referred to their clinic had been treated with ECT; without presenting data on these cases, the authors state that limited published reports of benefit in patients with OCD receiving ECT suggests that the treatment is inappropriate for this condition [103]. In contrast, another early report in patients with symptoms resembling OCD, obsessional neurosis, who had been refractory to standard treatments, included a response rate of approximately $40 \%$ in 80 patients following treatment with ECT combined with medication treatment seeking to increase sleep (narcosis) and antidepressants [104]; these authors argued that this technique should be tried prior to leukotomy. However, Jenike et al. [105] reported that $27 / 33$ patients who received cingulotomy were previously treated with ECT; of these, 7 received additional treatments with ECT following surgery. Good symptomatic response to ECT has more recently been reported in cases with atypical clinical characteristics (e.g., acute and late onset) $[106,107]$ or with catatonia [108]. Case reports of patients with OCD and Tourette's or other psychiatric comorbidities also suggest efficacy of ECT in reducing symptoms and maintaining improvement [109-116]. Additional cases of favorable response to ECT in patients with medication-refractory OCD have been reported, though others state that an undefined large number of patients were referred to their clinic who had previously failed to respond to ECT, arguing that the benefits derived from ECT may be more related to comorbid psychiatric illnesses [117]. Yet, an open trial found symptomatic benefit in $7 / 9$ patients with no depressive symptoms prior to OCD who received unilateral or bilateral ECT [118]. Symptom resolution in 1 responder was ultimately maintained using ECT, without medications [119]. A retrospective analysis of 13 depressed and 19 nondepressed patients with OCD who received ECT also demonstrated significant improvements in obsessive-compulsive symptoms in both groups, independent of improvements in depressive symptoms [120].

\section{Transcranial Magnetic Stimulation}

Transcranial magnetic stimulation (TMS) has a lower risk profile than either of the techniques discussed above, with side effects largely confined to sensations in the skin and headaches, though seizures are a possible risk, and earplugs are often provided to limit the risks of hearing damage. Repetitive TMS (rTMS) to the DLPFC has generally failed to demonstrate superiority over sham. Despite initial reports from open studies [121], multiple sham-controlled studies of rTMS to the DLPFC at 1 or $10 \mathrm{~Hz}, 110 \%$ motor threshold (MT), found no benefit of active treatment over placebo 
[122-124]. This lack of benefit was replicated in a group of 30 patients receiving active or sham rTMS of the right DLPFC [125]. However, a sham-controlled trial of rTMS of the DLPFC, at $80 \%$ MT with frequency defined based on the patient's intrinsic alpha EEG, found significant improvements in obsessions but not compulsions, with decreases in Y-BOCS scores, as well as symptoms of depression and anxiety [126].

Yet the supplementary motor area (SMA) appears to be a more promising target. Open rTMS to the SMA was also found to provide benefit in several reports with medicationresistant OCD [127, 128]. This finding was replicated in 2 sham-controlled trials ( $n=22$ and $n=18$, respectively) of rTMS to the SMA. One demonstrated a $41 \%$ response rate following active treatment and a mean reduction of $35 \%$ in YBOCS score versus a $10 \%$ response rate following sham treatment; the other reported a response rate of $67 \%$ following active treatment compared with $22 \%$ following sham [129, 130]. Although effects on neuronal function and response rates have been associated with symptomatic improvement, significant differences between active and sham treatment in all outcome measures have not been uniformly demonstrated [131]. Ongoing studies of TMS at this site may address these concerns (e.g., clinicaltrials.gov NCT00106249).

The OFC has also been suggested as a target for TMS. The only identified published report of TMS at this target, a 23patient single-blind sham-controlled trial of rTMS to the left OFC ( $1 \mathrm{~Hz}, 80 \% \mathrm{MT})$, failed to find a difference between groups at 3 weeks but found significant differences between groups in reduction of Y-BOCS score over 3 months following 3 weeks of active treatment [132].

\section{Other Methods}

A variety of other neuromodulatory treatments, including magnetic seizure therapy (see NCT01596608), have also been proposed, but data for OCD are not available. Prefrontal stimulation using a TMS coil designed to reach deeper structures (deep TMS) has also been piloted and an ongoing trial is examining effects of prefrontal stimulation intended to also affect the ACC (NCT01343732). Based on reports of anxiolytic effects in treatment trials for depression, a preliminary study of VNS for anxiety disorders was initiated; this open trial included 7 patients with OCD, 3 of whom were classified as responders based on $\mathrm{a} \geq 25 \%$ decrease in Y-BOCS score [133]. The authors suggested that double-blind trials may be warranted, but, to our knowledge, these have not been reported.

\section{Conclusions}

Important advances have been made in neuromodulation for OCD. These include localized treatments, such as DBS, that are reversible and can allow patients to serve as their own controls. Advances in ECT reduce risk and may provide a less invasive alternative to surgical modulation. Another neuromodulatory option that is less invasive and can be feasibly and ethically used in sham-controlled studies is TMS. Neuromodulation, compared with medications, limits the risks of systemic side effects and may provide advantages in "target engagement". Yet, challenges remain to reconcile current views of psychiatric pathophysiology with the potential of anatomically localized treatments. These localized treatments may work by altering circuit function, and may act at a distance. For example, DBS can elicit antidromic activation and can involve both GABAergic and glutamatergic transmission [134].

Importantly, because emotion and behavior are likely not localized to discrete centers, but rely on communication between multiple neuronal circuits, neuromodulatory approaches must be continually refined to affect more specific regions that may be spatially distributed throughout the brain. Though it is likely that local stimulation propagates up- or downstream through brain circuits, the incomplete efficacy of DBS treatment may relate to the spatially restricted effects of focal treatments on larger circuits. However, the benefits of ECT may be limited by effects on other brain functions, such as memory. Similarly, TMS may be limited by its impact on surrounding structures. Multiple stereotactic targets, closedloop systems that provide stimulation only when needed [135], more portable noninvasive stimulation methods, or combinations of neuromodulatory strategies may be required to provide optimal benefit in circuit adjustment and symptom resolution; patient-controlled temporal regulation of stimulation has already been attempted in OCD patients receiving DBS. Larger, well-controlled studies are needed to improve understanding of the potential for neuromodulatory treatments in OCD.

Growth in understanding of OCD has facilitated development of our current treatments from more crude approaches. Unfortunately, many patients with OCD remain ill and impaired despite receiving currently state-of-the-art treatment [136]. In this resistant group, TMS may provide an option with limited risk. Also, ECT may be considered prior to more invasive treatments. For highly-resistant patients, DBS may provide a critical somatic alternative. Tools for understanding psychiatric pathophysiology are also developing rapidly. Techniques such as PET, fMRI, magnetic resonance spectroscopy, magnetoencephalography, and quantitative EEG noninvasively illuminate human brain function in vivo. Knowledge gained from these techniques and ongoing research will facilitate novel treatment development and targeting. This offers the promise of improving the lives of patients who suffer from OCD.

Required Author Forms Disclosure forms provided by the authors are available with the online version of this article. 


\section{References}

1. Murray CJL, Lopez AD, Harvard School of Public Health., World Health Organization, World Bank. The global burden of disease: A comprehensive assessment of mortality and disability from diseases, injuries, and risk factors in 1990 and projected to 2020. Harvard School of Public Health on behalf of the World Health Organization and the World Bank, Cambridge, MA, 1996.

2. Kessler RC, Berglund P, Demler O, Jin R, Merikangas KR, Walters EE. Lifetime prevalence and age-of-onset distributions of DSM-IV disorders in the National Comorbidity Survey Replication. Arch Gen Psychiatry 2005;62:593-602.

3. American Psychiatric Association, American Psychiatric Association. Task Force on DSM-IV. Diagnostic and statistical manual of mental disorders: DSM-IV. 4th ed. American Psychiatric Association, Washington, DC, 1994.

4. Van Ameringen M, Patterson B, Simpson W. DSM-5 obsessivecompulsive and related disorders: clinical implications of new criteria. Depress Anxiety 2014;31:487-493.

5. Langston JW, Ballard P, Tetrud JW, Irwin I. Chronic Parkinsonism in humans due to a product of meperidine-analog synthesis. Science 1983;219:979-980.

6. Wright JM, Wall RA, Perry TL, Paty DW. Chronic parkinsonism secondary to intranasal administration of a product of meperidineanalogue synthesis. N Engl J Med 1984;310:325.

7. Alexander GE, DeLong MR, Strick PL. Parallel organization of functionally segregated circuits linking basal ganglia and cortex. Annu Rev Neurosci 1986;9:357-381.

8. Milad MR, Rauch SL. Obsessive-compulsive disorder: beyond segregated cortico-striatal pathways. Trends Cogn Sci 2012;16:43-51.

9. Saxena S, Rauch SL. Functional neuroimaging and the neuroanatomy of obsessive-compulsive disorder. Psychiatr Clin North Am 2000;23:563-586.

10. Krack P, Hariz MI, Baunez C, Guridi J, Obeso JA. Deep brain stimulation: from neurology to psychiatry? Trends Neurosci 2010;33:474-484.

11. Hansen ES, Hasselbalch S, Law I, Bolwig TG. The caudate nucleus in obsessive-compulsive disorder. Reduced metabolism following treatment with paroxetine: a PET study. Int J Neuropsychopharmacol 2002;5:1-10.

12. Cummings JL, Frankel M. Gilles de la Tourette syndrome and the neurological basis of obsessions and compulsions. Biol Psychiatry 1985;20:117-126.

13. Coffey BJ, Miguel EC, Biederman J, et al. Tourette's disorder with and without obsessive-compulsive disorder in adults: are they different? J Nerv Ment Dis 1998;186:201-206.

14. Worbe Y, Mallet L, Golmard JL, et al. Repetitive behaviours in patients with Gilles de la Tourette syndrome: Tics, compulsions, or both? PLoS One 2010;5:e12959.

15. Singer HS. Neurobiology of Tourette syndrome. Neurol Clin 1997;15:357-379.

16. Felling RJ, Singer HS. Neurobiology of tourette syndrome: current status and need for further investigation. J Neurosci 2011;31: 12387-12395.

17. Soomro GM, Altman D, Rajagopal S, Oakley-Browne M. Selective serotonin re-uptake inhibitors (SSRIs) versus placebo for obsessive compulsive disorder (OCD). Cochrane Database Syst Rev 2008: CD001765.

18. Sugden K, Tichopad A, Khan N, Craig IW, D'Souza UM. Genes within the serotonergic system are differentially expressed in human brain. BMC Neurosci 2009; 10:50

19. Goodman WK, McDougle CJ, Price LH, Riddle MA, Pauls DL, Leckman JF. Beyond the serotonin hypothesis: a role for dopamine in some forms of obsessive compulsive disorder? J Clin Psychiatry 1990;51(Suppl.):36-43.
20. van der Wee NJ, Stevens H, Hardeman JA, et al. Enhanced dopamine transporter density in psychotropic-naive patients with obsessive-compulsive disorder shown by [123I]\{beta\}-CIT SPECT. Am J Psychiatry 2004;161:2201-2206.

21. Denys D, van der Wee N, Janssen J, De Geus F, Westenberg HG. Low level of dopaminergic D2 receptor binding in obsessivecompulsive disorder. Biol Psychiatry 2004;55:1041-1045.

22. Haber SN, McFarland NR. The concept of the ventral striatum in nonhuman primates. Ann N Y Acad Sci 1999;877:33-48.

23. Rosenberg DR, MacMaster FP, Keshavan MS, Fitzgerald KD, Stewart CM, Moore GJ. Decrease in caudate glutamatergic concentrations in pediatric obsessive-compulsive disorder patients taking paroxetine. J Am Acad Child Adolesc Psychiatry 2000;39:1096-1103.

24. Arnold PD, Rosenberg DR, Mundo E, Tharmalingam S, Kennedy JL, Richter MA. Association of a glutamate (NMDA) subunit receptor gene (GRIN2B) with obsessive-compulsive disorder: a preliminary study. Psychopharmacology (Berl) 2004;174:530-538.

25. Arnold PD, Sicard T, Burroughs E, Richter MA, Kennedy JL. Glutamate transporter gene SLC1A1 associated with obsessivecompulsive disorder. Arch Gen Psychiatry 2006;63:769-776.

26. Dickel DE, Veenstra-VanderWeele J, Cox NJ, Wu X, Fischer DJ, Van Etten-Lee M, et al. Association testing of the positional and functional candidate gene SLC1A1/EAAC1 in early-onset obsessive-compulsive disorder. Arch Gen Psychiatry 2006;63:778-785.

27. Wendland JR, Moya PR, Timpano KR, Anavitarte AP, Kruse MR, Wheaton $\mathrm{MG}$, et al. A haplotype containing quantitative trait loci for SLC1A1 gene expression and its association with obsessivecompulsive disorder. Arch Gen Psychiatry 2009;66:408-416.

28. Coric V, Taskiran S, Pittenger C, et al. Riluzole augmentation in treatment-resistant obsessive-compulsive disorder: an open-label trial. Biol Psychiatry 2005;58:424-428.

29. Lafleur DL, Pittenger C, Kelmendi B, et al. N-acetylcysteine augmentation in serotonin reuptake inhibitor refractory obsessive-compulsive disorder. Psychopharmacology (Berl) 2006;184:254-256.

30. Grant JE, Odlaug BL, Kim SW. N-acetylcysteine, a glutamate modulator, in the treatment of trichotillomania: a double-blind, placebo-controlled study. Arch Gen Psychiatry 2009;66:756-763.

31. Rodriguez CI, Kegeles LS, Levinson A, et al. Randomized controlled crossover trial of ketamine in obsessive-compulsive disorder: proof-of-concept. Neuropsychopharmacology 2013;38:2475-2483.

32. Rauch SL. Neuroimaging and neurocircuitry models pertaining to the neurosurgical treatment of psychiatric disorders. Neurosurg Clin N Am 2003; 14:213-223.

33. Breiter HC, Rauch SL, Kwong KK, et al. Functional magnetic resonance imaging of symptom provocation in obsessivecompulsive disorder. Arch Gen Psychiatry 1996;53:595-606.

34. Penney JB, Jr., Young AB. GABA as the pallidothalamic neurotransmitter: implications for basal ganglia function. Brain Res 1981;207:195-199.

35. Koob GF, Swerdlow NR. The functional output of the mesolimbic dopamine system. Ann N Y Acad Sci 1988;537:216-227.

36. Barroso-Chinea P, Rico AJ, Perez-Manso M, et al. Glutamatergic pallidothalamic projections and their implications in the pathophysiology of Parkinson's disease. Neurobiol Dis 2008;31:422-432.

37. Wallman MJ, Gagnon D, Parent M. Serotonin innervation of human basal ganglia. Eur J Neurosci 2011;33:1519-1532.

38. Nikolaus S, Antke C, Beu M, Muller HW. Cortical GABA, striatal dopamine and midbrain serotonin as the key players in compulsive and anxiety disorders - results from in vivo imaging studies. Rev Neurosci 2010;21:119-139.

39. Papez JW. A proposed mechanism of emotion. 1937. J Neuropsychiatry Clin Neurosci 1995;7:103-112.

40. Saxena S, Brody AL, Maidment KM, et al. Localized orbitofrontal and subcortical metabolic changes and predictors of response to paroxetine treatment in obsessive-compulsive disorder. Neuropsychopharmacology 1999;21:683-693. 
41. Nakao T, Nakagawa A, Yoshiura T, et al. Brain activation of patients with obsessive-compulsive disorder during neuropsychological and symptom provocation tasks before and after symptom improvement: a functional magnetic resonance imaging study. Biol Psychiatry 2005;57:901-910.

42. Le Jeune F, Verin M, N'Diaye K, et al. Decrease of prefrontal metabolism after subthalamic stimulation in obsessive-compulsive disorder: a positron emission tomography study. Biol Psychiatry 2010;68:1016-1022.

43. Hitchcock ER, Ballantine HT, Meyerson BA. Modern concepts in psychiatric surgery. In: Proceedings of the 5th World Congress of Psychiatric Surgery, Boston, MA, USA, August 21-25, 1978. Elsevier/North-Holland Biomedical Press, New York, Amsterdam.

44. Laitinen LV. Emotional responses to subcortical electrical stimulation in psychiatric patients. Clin Neurol Neurosurg 1979;81:148-157.

45. Ardouin C, Pillon B, Peiffer E, et al. Bilateral subthalamic or pallidal stimulation for Parkinson's disease affects neither memory nor executive functions: a consecutive series of 62 patients. Ann Neurol 1999;46:217-223.

46. Woods SP, Fields JA, Troster AI. Neuropsychological sequelae of subthalamic nucleus deep brain stimulation in Parkinson's disease: A critical review. Neuropsychol Rev 2002;12:111-126.

47. Heath RG. Pleasure and brain activity in man. Deep and surface electroencephalograms during orgasm. J Nerv Ment Dis 1972;154: 3-18.

48. Mallet L, Mesnage V, Houeto JL, et al. Compulsions, Parkinson's disease, and stimulation. Lancet 2002;360:1302-1304.

49. Fontaine D, Mattei V, Borg M, et al. Effect of subthalamic nucleus stimulation on obsessive-compulsive disorder in a patient with Parkinson disease. Case report. J Neurosurg 2004;100:1084-1086.

50. Bejjani BP, Damier P, Arnulf I, et al. Transient acute depression induced by high-frequency deep-brain stimulation. N Engl J Med 1999;340:1476-1480.

51. Tommasi G, Lanotte M, Albert U, et al. Transient acute depressive state induced by subthalamic region stimulation. J Neurol Sci 2008;273:135-138.

52. Temel Y. Limbic effects of high-frequency stimulation of the subthalamic nucleus. Vitam Horm 2010;82:47-63.

53. Temel Y, Kessels A, Tan S, Topdag A, Boon P, Visser-Vandewalle V. Behavioural changes after bilateral subthalamic stimulation in advanced Parkinson disease: a systematic review. Parkinsonism Relat Disord 2006;12:265-272.

54. Witt K, Daniels C, Reiff J, et al. Neuropsychological and psychiatric changes after deep brain stimulation for Parkinson's disease: a randomised, multicentre study. Lancet Neurol 2008;7:605-614.

55. Mallet L, Schupbach M, N'Diaye K, et al. Stimulation of subterritories of the subthalamic nucleus reveals its role in the integration of the emotional and motor aspects of behavior. Proc Natl Acad Sci U S A 2007;104:10661-10666.

56. Higginson CI, Fields JA, Troster AI. Which symptoms of anxiety diminish after surgical interventions for Parkinson disease? Neuropsychiatry Neuropsychol Behav Neurol 2001;14:117-121.

57. Kosel M, Sturm V, Frick C, et al. Mood improvement after deep brain stimulation of the internal globus pallidus for tardive dyskinesia in a patient suffering from major depression. J Psychiatr Res 2007;41:801-803.

58. Lapidus KA, Kopell BH, Ben-Haim S, Rezai AR, Goodman WK. History of psychosurgery: A psychiatrist's perspective. World Neurosurg 2013;80:S27, e1-16.

59. Goodman WK, Alterman RL. Deep brain stimulation for intractable psychiatric disorders. Annu Rev Med 2012;63:511-524.

60. Blomstedt P, Sjoberg RL, Hansson M, Bodlund O, Hariz MI. Deep brain stimulation in the treatment of obsessive-compulsive disorder. World Neurosurg 2013;80:e245-253.

61. Nangunoori R, Tomycz ND, Quigley M, Oh MY, Whiting DM. Deep brain stimulation for psychiatric diseases: a pooled analysis of published studies employing disease-specific standardized outcome scales. Stereotact Funct Neurosurg 2013;91:345-354.

62. Nuttin B, Cosyns P, Demeulemeester H, Gybels J, Meyerson B. Electrical stimulation in anterior limbs of internal capsules in patients with obsessive-compulsive disorder. Lancet 1999;354: 1526.

63. Vandewalle V, van der Linden C, Groenewegen HJ, Caemaert J. Stereotactic treatment of Gilles de la Tourette syndrome by high frequency stimulation of thalamus. Lancet 1999;353:724.

64. Gabriels L, Cosyns P, Nuttin B, Demeulemeester H, Gybels J. Deep brain stimulation for treatment-refractory obsessive-compulsive disorder: psychopathological and neuropsychological outcome in three cases. Acta Psychiatr Scand 2003;107:275-282.

65. Goodman WK, Price LH, Rasmussen SA, et al. The Yale-Brown Obsessive Compulsive Scale. I. Development, use, and reliability. Arch Gen Psychiatry 1989;46:1006-1011.

66. Anderson D, Ahmed A. Treatment of patients with intractable obsessive-compulsive disorder with anterior capsular stimulation. Case report. J Neurosurg 2003;98:1104-1108.

67. Aouizerate B, Cuny E, Martin-Guehl C, et al. Deep brain stimulation of the ventral caudate nucleus in the treatment of obsessivecompulsive disorder and major depression. Case report. J Neurosurg 2004;101:682-686.

68. Aouizerate B, Martin-Guehl C, Cuny E, et al. Deep brain stimulation for OCD and major depression. Am J Psychiatry 2005;162:2192.

69. Nuttin BJ, Gabriels LA, Cosyns PR, et al. Long-term electrical capsular stimulation in patients with obsessive-compulsive disorder. Neurosurgery 2003;52:1263-1272.

70. Nuttin BJ, Gabriels LA, Cosyns PR, et al. Long-term electrical capsular stimulation in patients with obsessive-compulsive disorder. Neurosurgery 2008;62(6 Suppl. 3):966-977.

71. Aouizerate B, Cuny E, Bardinet E, et al. Distinct striatal targets in treating obsessive-compulsive disorder and major depression. $\mathrm{J}$ Neurosurg 2009;111:775-779.

72. Chang WS, Roh D, Kim CH, Chang JW. Combined bilateral anterior cingulotomy and ventral capsule/ventral striatum deep brain stimulation for refractory obsessive-compulsive disorder with major depression: do combined procedures have a long-term benefit? Restor Neurol Neurosci 2013;31:723-732.

73. Greenberg BD, Gabriels LA, Malone DA, Jr., et al. Deep brain stimulation of the ventral internal capsule/ventral striatum for obsessive-compulsive disorder: Worldwide experience. Mol Psychiatry 2010;15:64-79.

74. Abelson JL, Curtis GC, Sagher O, et al. Deep brain stimulation for refractory obsessive-compulsive disorder. Biol Psychiatry 2005;57: $510-516$.

75. Goodman WK, Foote KD, Greenberg BD, et al. Deep brain stimulation for intractable obsessive compulsive disorder: pilot study using a blinded, staggered-onset design. Biol Psychiatry 2010;67: 535-542.

76. Okun MS, Mann G, Foote KD, et al. Deep brain stimulation in the internal capsule and nucleus accumbens region: responses observed during active and sham programming. J Neurol Neurosurg Psychiatry 2007;78:310-314.

77. Chang CH, Chen SY, Hsiao YL, Tsai ST, Tsai HC. Hypomania with hypersexuality following bilateral anterior limb stimulation in obsessive-compulsive disorder. J Neurosurg 2010;112:1299-1300.

78. Okun MS, Bowers D, Springer U, et al. What's in a "smile?" Intraoperative observations of contralateral smiles induced by deep brain stimulation. Neurocase 2004;10:271-279.

79. Haq IU, Foote KD, Goodman WG, et al. Smile and laughter induction and intraoperative predictors of response to deep brain stimulation for obsessive-compulsive disorder. Neuroimage 2011;54(Suppl. 1):S247-S255.

80. Tsai HC, Chang CH, Pan JI, et al. Acute stimulation effect of the ventral capsule/ventral striatum in patients with refractory 
obsessive-compulsive disorder - a double-blinded trial. Neuropsychiatr Dis Treat 2014;10:63-69.

81. Haq IU, Foote KD, Goodman WK, et al. A case of mania following deep brain stimulation for obsessive compulsive disorder. Stereotact Funct Neurosurg 2010;88:322-328.

82. Baker KB, Kopell BH, Malone D, et al. Deep brain stimulation for obsessive-compulsive disorder: using functional magnetic resonance imaging and electrophysiological techniques: technical case report. Neurosurgery 2007;61(5 Suppl. 2):E367-E368.

83. Vora AK, Ward H, Foote KD, Goodman WK, Okun MS. Rebound symptoms following battery depletion in the NIH OCD DBS cohort: clinical and reimbursement issues. Brain Stimul 2012;5:599-604.

84. Tsai HC, Chang CH, Pan JI, et al. Pilot study of deep brain stimulation in refractory obsessive-compulsive disorder ethnic Chinese patients. Psychiatry Clin Neurosci 2012;66:303-312.

85. Roh D, Chang WS, Chang JW, Kim CH. Long-term follow-up of deep brain stimulation for refractory obsessive-compulsive disorder. Psychiatry Res 2012;200:1067-1070.

86. Kubu CS, Malone DA, Chelune G, et al. Neuropsychological outcome after deep brain stimulation in the ventral capsule/ventral striatum for highly refractory obsessive-compulsive disorder or major depression. Stereotact Funct Neurosurg 2013;91:374-378.

87. van den Munckhof P, Bosch DA, Mantione MH, Figee M, Denys DA, Schuurman PR. Active stimulation site of nucleus accumbens deep brain stimulation in obsessive-compulsive disorder is localized in the ventral internal capsule. Acta Neurochir Suppl 2013;117:53-59.

88. Sturm V, Lenartz D, Koulousakis A, et al. The nucleus accumbens: a target for deep brain stimulation in obsessive-compulsive- and anxiety-disorders. J Chem Neuroanat 2003;26:293-299.

89. Franzini A, Messina G, Gambini O, et al. Deep-brain stimulation of the nucleus accumbens in obsessive compulsive disorder: clinical, surgical and electrophysiological considerations in two consecutive patients. Neurol Sci 2010;31:353-359.

90. Huff W, Lenartz D, Schormann M, et al. Unilateral deep brain stimulation of the nucleus accumbens in patients with treatmentresistant obsessive-compulsive disorder: Outcomes after one year. Clin Neurol Neurosurg 2010;112:137-143.

91. Greenberg BD, Malone DA, Friehs GM, et al. Three-year outcomes in deep brain stimulation for highly resistant obsessive-compulsive disorder. Neuropsychopharmacology 2006;31:2384-2393.

92. Denys D, Mantione M, Figee M, et al. Deep brain stimulation of the nucleus accumbens for treatment-refractory obsessive-compulsive disorder. Arch Gen Psychiatry 2010;67:1061-1068.

93. Luigjes J, Mantione M, van den Brink W, Schuurman PR, van den Munckhof P, Denys D. Deep brain stimulation increases impulsivity in two patients with obsessive-compulsive disorder. Int Clin Psychopharmacol 2011;26:338-340.

94. de Koning PP, Figee M, Endert E, Storosum JG, Fliers E, Denys D. Deep brain stimulation for obsessive-compulsive disorder is associated with cortisol changes. Psychoneuroendocrinology 2013;38: $1455-1459$.

95. Ooms P, Mantione M, Figee M, Schuurman PR, van den Munckhof P, Denys D. Deep brain stimulation for obsessive-compulsive disorders: Long-term analysis of quality of life. J Neurol Neurosurg Psychiatry 2014;85:153-158.

96. Mallet L, Polosan M, Jaafari N, et al. Subthalamic nucleus stimulation in severe obsessive-compulsive disorder. N Engl J Med 2008;359:2121-2134.

97. Chabardes S, Polosan M, Krack P, et al. Deep brain stimulation for obsessive-compulsive disorder: subthalamic nucleus target. World Neurosurg 2013;80:S31, e1-e8.

98. Piallat B, Polosan M, Fraix V, et al. Subthalamic neuronal firing in obsessive-compulsive disorder and Parkinson disease. Ann Neurol 2011;69:793-802.

99. Welter ML, Burbaud P, Fernandez-Vidal S, et al. Basal ganglia dysfunction in OCD: subthalamic neuronal activity correlates with symptoms severity and predicts high-frequency stimulation efficacy. Transl Psychiatry 2011;1:e5.

100. Jimenez-Ponce F, Velasco-Campos F, Castro-Farfan G, et al. Preliminary study in patients with obsessive-compulsive disorder treated with electrical stimulation in the inferior thalamic peduncle. Neurosurgery 2009;65(6 Suppl.):203-209.

101. Jimenez F, Nicolini H, Lozano AM, Piedimonte F, Salin R, Velasco F. Electrical stimulation of the inferior thalamic peduncle in the treatment of major depression and obsessive compulsive disorders. World Neurosurg 2013;80:S30, e17-25.

102. Grimshaw L. The outcome of obsessional disorder. A follow-up study of 100 cases. Br J Psychiatry 1965;111:1051-1056.

103. Janike MA, Baer L, Minichiello WE. Somatic treatments for obsessive-compulsive disorders. Compr Psychiatry 1987;28:250 263.

104. Walter CJ, Mitchell-Heggs N, Sargant W. Modified narcosis, ECT and antidepressant drugs: a review of technique and immediate outcome. Br J Psychiatry 1972;120:651-662.

105. Jenike MA, Baer L, Ballantine T, et al. Cingulotomy for refractory obsessive-compulsive disorder. A long-term follow-up of 33 patients. Arch Gen Psychiatry 1991;48:548-555.

106. Swartz CM, Shen WW. Is episodic obsessive compulsive disorder bipolar? A report of four cases. J Affect Disord 1999;56:61-66.

107. Mellman LA, Gorman JM. Successful treatment of obsessivecompulsive disorder with ECT. Am J Psychiatry 1984;141:596597.

108. D'Urso G, Mantovani A, Barbarulo AM, Labruna L, Muscettola G. Brain-behavior relationship in a case of successful ECT for drug refractory catatonic OCD. J Ect 2012;28:190-193.

109. Hanisch F, Friedemann J, Piro J, Gutmann P. Maintenance electroconvulsive therapy for comorbid pharmacotherapy-refractory obsessive-compulsive and schizoaffective disorder. Eur J Med Res 2009;14:367-368.

110. Casey DA, Davis MH. Obsessive-compulsive disorder responsive to electroconvulsive therapy in an elderly woman. South Med J 1994;87:862-864.

111. Bulbul F, Copoglu US, Alpak G, Unal A, Tastan MF, Savas HA. Maintenance therapy with electroconvulsive therapy in a patient with a codiagnosis of bipolar disorder and obsessive-compulsive disorder. J Ect 2013;29:e21-e22.

112. Strassnig M, Riedel M, Muller N. Electroconvulsive therapy in a patient with Tourette's syndrome and co-morbid Obsessive Compulsive Disorder. World J Biol Psychiatry 2004;5:164-166.

113. Gadit AM, Smigas T. Efficacy of ECT in severe obsessivecompulsive disorder with Parkinson's disease. BMJ Case Rep 2012;2012.

114. Lavin MR, Halligan P. ECT for comorbid obsessive-compulsive disorder and schizophrenia. Am J Psychiatry 1996;153:1652-1653.

115. Chaves MP, Crippa JA, Morais SL, Zuardi AW. Electroconvulsive therapy for coexistent schizophrenia and obsessive-compulsive disorder. J Clin Psychiatry 2005;66:542-543.

116. Thomas SG, Kellner $\mathrm{CH}$. Remission of major depression and obsessive-compulsive disorder after a single unilateral ECT. J Ect 2003; 19:50-51.

117. Beale MD, Kellner CH, Pritchett JT, Burns CM. ECT for OCD. J Clin Psychiatry 1995;56:81-82.

118. Khanna S, Gangadhar BN, Sinha V, Rajendra PN, Channabasavanna SM. Electroconvulsive therapy in obsessivecompulsive disorder. Convuls Ther 1988;4:314-320.

119. Husain MM, Lewis SF, Thornton WL. Maintenance ECT for refractory obsessive-compulsive disorder. Am J Psychiatry 1993;150: 1899-1900.

120. Maletzky B, McFarland B, Burt A. Refractory obsessive compulsive disorder and ECT. Convuls Ther 1994;10:34-42.

121. Greenberg BD, George MS, Martin JD, et al. Effect of prefrontal repetitive transcranial magnetic stimulation in obsessive- 
compulsive disorder: A preliminary study. Am J Psychiatry 1997;154:867-869.

122. Sarkhel S, Sinha VK, Praharaj SK. Adjunctive high-frequency right prefrontal repetitive transcranial magnetic stimulation (rTMS) was not effective in obsessive-compulsive disorder but improved secondary depression. J Anxiety Disord 2010;24:535-539.

123. Kang JI, Kim CH, Namkoong K, Lee CI, Kim SJ. A randomized controlled study of sequentially applied repetitive transcranial magnetic stimulation in obsessive-compulsive disorder. J Clin Psychiatry 2009;70:1645-1651.

124. Alonso P, Pujol J, Cardoner N, et al. Right prefrontal repetitive transcranial magnetic stimulation in obsessive-compulsive disorder: a double-blind, placebo-controlled study. Am J Psychiatry 2001;158:1143-1145.

125. Mansur CG, Myczkowki ML, de Barros Cabral S, et al. Placebo effect after prefrontal magnetic stimulation in the treatment of resistant obsessive-compulsive disorder: a randomized controlled trial. Int J Neuropsychopharmacol 2011;14:1389-1397.

126. Ma X, Huang Y, Liao L, Jin Y. A randomized double-blinded shamcontrolled trial of alpha electroencephalogram-guided transcranial magnetic stimulation for obsessive-compulsive disorder. Chin Med J (Engl) 2014;127:601-606.

127. Kumar N, Chadda RK. Augmentation effect of repetitive transcranial magnetic stimulation over the supplementary motor cortex in treatment refractory patients with obsessive compulsive disorder. Indian J Psychiatry 2011;53:340-342.

128. Mantovani A, Lisanby SH, Pieraccini F, Ulivelli M, Castrogiovanni P, Rossi S. Repetitive transcranial magnetic stimulation (rTMS) in the treatment of obsessive-compulsive disorder (OCD) and Tourette's syndrome (TS). Int J Neuropsychopharmacol 2006;9:95-100.
129. Gomes PV, Brasil-Neto JP, Allam N, Rodrigues de Souza E. A randomized, double-blind trial of repetitive transcranial magnetic stimulation in obsessive-compulsive disorder with three-month follow-up. J Neuropsychiatry Clin Neurosci 2012;24:437-443.

130. Mantovani A, Simpson HB, Fallon BA, Rossi S, Lisanby SH. Randomized sham-controlled trial of repetitive transcranial magnetic stimulation in treatment-resistant obsessive-compulsive disorder. Int J Neuropsychopharmacol 2010;13:217-227.

131. Mantovani A, Rossi S, Bassi BD, Simpson HB, Fallon BA, Lisanby $\mathrm{SH}$. Modulation of motor cortex excitability in obsessivecompulsive disorder: an exploratory study on the relations of neurophysiology measures with clinical outcome. Psychiatry Res 2013;210:1026-1032.

132. Ruffini C, Locatelli M, Lucca A, Benedetti F, Insacco C, Smeraldi E. Augmentation effect of repetitive transcranial magnetic stimulation over the orbitofrontal cortex in drug-resistant obsessivecompulsive disorder patients: a controlled investigation. Prim Care Companion J Clin Psychiatry. 2009;11:226-230.

133. George MS, Ward HE, Jr., Ninan PT, et al. A pilot study of vagus nerve stimulation (VNS) for treatment-resistant anxiety disorders. Brain Stimul 2008;1:112-121.

134. McCracken CB, Grace AA. High-frequency deep brain stimulation of the nucleus accumbens region suppresses neuronal activity and selectively modulates afferent drive in rat orbitofrontal cortex in vivo. J Neurosci 2007;27:12601-12610.

135. Morrell MJ. Responsive cortical stimulation for the treatment of medically intractable partial epilepsy. Neurology 2011;77:12951304.

136. Skoog G, Skoog I. A 40-year follow-up of patients with obsessivecompulsive disorder. Arch Gen Psychiatry 1999;56:121-127. 